Original Article

\title{
Effect of a muscle strengthening exercise program for pelvic control on gait function of stroke patients
}

\author{
Byoung-Sun Park PT, MS ${ }^{1) a}$, Ju-Hyun Kim, PT, PhD ${ }^{1) a}$, Mee-Young Kim, PT, PhD ${ }^{1)}$, \\ Lim-Kyu Lee, PT, MS ${ }^{1)}$, Seung-Min Yang, PT, MS'1), Hye-Joo Jeon, PT, MS ${ }^{1)}$, \\ Won-Deok Lee, PT, MS ${ }^{1)}$, Ji-Woong Noh, PT, MS ${ }^{1)}$, Jeong-Uk Lee, PT, PhD ${ }^{2)}$, \\ Taek-Yong Kwak, $\mathrm{PhD}^{3)}$, Tae-Hyun Lee, $\mathrm{PhD}^{4)}$, Ju-Young Kim, $\mathrm{PhD}^{4}$, \\ JUNGHWAN KIM, PT, PhD ${ }^{5 *}$ \\ 1) Laboratory of Health Science and Nanophysiotherapy, Department of Physical Therapy, Graduate \\ School, Yongin University, Republic of Korea \\ 2) Department of Physical Therapy, College of Health Science, Honam University, Republic of Korea \\ 3) Department of Taekwondo Instructor Education, College of Martial Arts, Yongin University, Repub- \\ lic of Korea \\ 4) Department of Combative Martial Arts Training, College of Martial Arts, Yongin University, Repub- \\ lic of Korea \\ 5) Department of Physical Therapy, College of Public Health and Welfare, Yongin University: Yongin \\ 449-714, Republic of Korea
}

\begin{abstract}
Purpose] The purpose of this study was to investigate the effects of strengthening exercises for the hip extensors on the gait performance and stability of patients with hemiplegia. [Subjects and Methods] The subjects were fifteen stroke patients (ten males, five females). The experimental subjects performed a hip extensor strengthening exercise (HESE) program for a total of four weeks. [Results] The experimental subjects showed significant improvements after the HESE program. Especially, walking speed and the affected side stance phase time significantly increased after the HESE program. Furthermore, the affected side stride length and symmetry index in the stance phase significantly increased after HESE program. [Conclusion] These results suggest that the HESE program may, in part, help to improve gait performance ability and stabilize physical disability after stroke. Key words: Stroke patients, Hip extensor strengthening exercise (HESE) program, Gait function
\end{abstract}

(This article was submitted Aug. 21, 2014, and was accepted Oct. 7, 2014)

\section{INTRODUCTION}

Most hemiplegic patients who suffer from stroke experience restrictions on mobility at home and in the community, and they especially have difficulty with independent walking $^{1)}$. Turnbull et al. ${ }^{2)}$ suggested that the recovery of gait ability is an important goal of physical therapy for a stroke patient, because gait is an important element of functional independence. With regard to this, Mumman ${ }^{3)}$ suggest that the biggest loss after stroke is gait ability, and hemiplegic patients show disorders in the selective ability of regulated and coordinated movements, which results in a slow gait velocity and compensatory movements by the lower extremity of the unaffected side. Perry ${ }^{4}$ also suggested that hemiplegic patients show a short stride length and slow gait velocity for result of damage to the joint and to the regulatory function of

*Corresponding author. Junghwan Kim (E-mail: junghwankim3@yongin.ac.kr) ${ }^{\mathrm{T}} \mathrm{The}$ first 2 authors contributed equally to this work.

(C2015 The Society of Physical Therapy Science. Published by IPEC Inc. This is an open-access article distributed under the terms of the Creative Commons Attribution Non-Commercial No Derivatives (by-ncnd) License $<$ http://creativecommons.org/licenses/by-nc-nd/3.0/>. the muscles that are necessary for normal gait. Furthermore, gait is closely connected with the environment, since gait adapts and is modified to overcome obstacles and the varied geography that are faced during walking ${ }^{5)}$. Due to central nervous system damage, stroke patients show muscle weakness, abnormal muscle tone, and disorders of balance and posture control, which result in difficulty in the control of movement ${ }^{6)}$. For these reasons, problems occur with the quality and adaptation of the gait pattern, resulting from imbalance in the low extremity stance phase of the affected side and of the low extremity stance phase of the unaffected side, a decline in cadence and gait velocity, asymmetrical weight distribution, and a difference between step length and stride length ${ }^{7,8)}$. In particular, gait disorder after stroke reduces the functional independence level and results in a negative prognosis, which is a reason why regaining gait ability is a critical element directly connected with patients' independence and is one of the goals of rehabilitation ${ }^{9}$. Neurotherapy methods, which include Bobath therapy and proprioceptive neuromuscular facilitation, mainly focus on the control of abnormal muscle tone and of the asymmetrical movement which leads to gait disorder ${ }^{10)}$. These methods require many therapists and time, because they mainly consist of muscle strengthening movements in a static position 
Table 1. Clinical characteristics of the hemiplegic stroke patients

\begin{tabular}{cccccccc}
\hline $\begin{array}{c}\text { Age } \\
(\mathrm{yr})\end{array}$ & $\begin{array}{c}\text { Gender } \\
(\%)\end{array}$ & $\begin{array}{c}\text { Height } \\
(\mathrm{cm})\end{array}$ & $\begin{array}{c}\text { Weight } \\
(\mathrm{kg})\end{array}$ & $\begin{array}{c}\text { Cause of } \\
\text { disease }(\%)\end{array}$ & $\begin{array}{c}\text { AS } \\
(\%)\end{array}$ & $\begin{array}{c}\text { K-MMSE } \\
(\text { score })\end{array}$ & $\begin{array}{c}\text { Time post- } \\
\text { stroke (mo) }\end{array}$ \\
\hline $\begin{array}{c}\text { M 10 (66.7) } \\
\text { F 5 (33.3) }\end{array}$ & $168.5 \pm 2.1$ & $68.5 \pm 3.5$ & $\begin{array}{c}\text { In 12 (80.0) } \\
\text { He 3 (20.0) }\end{array}$ & $\begin{array}{c}\text { Rt 7 (46.7) } \\
\text { Lt 8 (53.3) }\end{array}$ & $26.5 \pm 2.5$ & $20.5 \pm 6.2$ \\
\hline
\end{tabular}

through manual handling by a therapist. However, studies on the effects of neurophysiotherapy performed by therapist handling are inconclusive. Therefore, we hypothesized that gait function would improve with pelvic control following a hip extensor strengthening exercise (HESE) program for the paretic lower extremity. We examined whether the HESE program promotes functional improvement of the paretic lower extremity of stroke patients.

\section{SUBJECTS AND METHODS}

The participants in this study were fifteen hemiplegic patients who had been diagnosed with stroke (Table 1) who were receiving inpatient or outpatient treatment at hospital $\mathrm{P}$ rehabilitation center. The following were the conditions for inclusion in the study. The present study had a single-group pre-post design. All the subjects participated in a four-week six-method hip extensor strengthening exercise (HESE) program. This program was performed by a therapist manipulating the subjects for about half an hour a day in the supine position, side-lying position, and prone position on a treatment table. The HESE program comprised six steps:

1. Hip extension and posterior tilt movement;

2. Rotation extension movement of both the legs;

3. Hip joint and pelvis movement using a therapeutic ball;

4. Hip joint and pelvis movement using a therapeutic ball;

5. Hip joint extension muscle strengthening movement in the side-lying position; and

6. Hip joint extension muscle strengthening movement in the prone position.

The program was performed three times a week for four weeks. Each session consisted of three sets of 15 performances of the 6-step program lasting about half an hour, with 30 seconds of relaxation time between the sets ${ }^{11)}$. Each participant was assessed by a physical therapist before and after the intervention in order to examine its effects on gait performance and stability. The $10-\mathrm{m}$ walking velocity test and the Berg Balance Scale (BBS) were used to evaluate the changes in gait performance and stability. BBS is a widely used clinical test which was developed to evaluate both the static and kinetic balance abilities of stroke patients. It consists of 14 assessment items: sitting to standing, standing without support, sitting without support, standing to sitting, transfers, standing with eyes closed, performing the Romberg test with eyes open, reaching, turning and looking over the shoulder, making $360^{\circ}$ turn to the right and left, and standing on one leg. Each item is scored from 1 to 5 . It has been shown that subjects with BBS scores $>41$ have a low risk of fall, medium risk of fall for BBS scores of 21-40, and high risk of fall for BBS scores of less than 20. BBS can be used to evaluate the balance ability of patients with hemiplegia caused either by senile disorder or stroke ${ }^{12)}$. A GAITRite (Gait trainer 2 analysis system, USA) was used to measure the spatiotemporal variables of gait (walking speed, walking cycle, affected side stance phase, stride length) and the symmetry index (stance phase, stride length). Subjects performed three trials for both pre- and post-test measurements. When GAITRite was used in the study, it helped the participants observe in real time their feet touching the ground on a monitor. GAITRite can compare gait velocity (meter/sec), gait cycle (cycle/sec), and the symmetry index $(\%)$ of the stance phase and the swing phase, with normal category values on a histogram ${ }^{13)}$. Statistical analyses were performed using SPSS Version 20.0. The Shapiro-Wilks test was used to verify the general and medical characteristics and the measured variables displayed a normal distribution. The assumption of a normal distribution was confirmed. All data are presented as mean \pm standard error. The chi-square was used to compare the general and medical characteristics of the participants and the paired t-test was conducted to compare the results of before and after the treatment. The statistical significance level was chosen as $\alpha=0.05$. The formulas for the symmetry indexes of the stance phase and stride length used in the study were: symmetric index of length (\%) $=$ non-affected side low extremity length $(\mathrm{cm}) /$ affected side low extremity length $(\mathrm{cm}) \times 100 \%$; and symmetric index of the stance phase $(\%)=$ affected side low extremity stance phase $(\mathrm{sec}) /$ non-affected side low extremity stance phase $(\mathrm{sec}) \times 100 \%$. The protocol of this study was approved by the Committee of Ethics in Research of the University of Yongin, in accordance with the terms of Resolution 5-1-20, December 2006. Furthermore, all subjects provided their informed consent to participation in the present study.

\section{RESULTS}

Table 1 summarizes the clinical characteristics of the subjects. Walking speed, stance phase and stride length of the affected side, and the symmetry index of the stance phase significantly improved after the HESE program $(\mathrm{p}<0.05)$ (Table 2).

\section{DISCUSSION}

The distinctive gait patterns of hemiplegic patients include a slow gait cycle and velocity, differences between the affected side and unaffected side step length, a short stance phase, and a relatively long swing phase on the affected side ${ }^{14,15)}$. Restoration of the ability to gait is a very important goal for stroke patients, and therefore, evaluating 
Table 2. Effects of hip extensor strengthening exercise program on the hemiplegic stroke patients

\begin{tabular}{lcc}
\hline \multirow{2}{*}{ Variables } & \multicolumn{2}{c}{ Hemiplegic stroke patients } \\
\cline { 2 - 3 } & Pre-HESE & Post-HESE \\
\hline Walking speed $(\mathrm{m} / \mathrm{sec})$ & $0.5 \pm 0.0$ & $0.6 \pm 0.0^{*}$ \\
Walking cycle $(\mathrm{c} / \mathrm{sec})$ & $0.6 \pm 0.0$ & $0.6 \pm 0.0$ \\
AS stance phase $(\mathrm{sec} / \%)$ & $47.0 \pm 1.2$ & $48.5 \pm 1.1^{*}$ \\
AS stride length (cm) & $38.1 \pm 3.0$ & $41.8 \pm 2.8^{*}$ \\
SI of stance phase (\%) & $90.0 \pm 4.2$ & $94.0 \pm 4.0^{*}$ \\
SI of stride length (\%) & $90.6 \pm 6.4$ & $93.1 \pm 5.7$ \\
10WVT (m/sec) & $29.8 \pm 11.8$ & $29.2 \pm 11.6$ \\
BBS (score) & $37.1 \pm 2.5$ & $37.3 \pm 2.8$ \\
\hline
\end{tabular}

Data are presented as means \pm SE. HESE: hip extensor strengthening exercise; AS: affected side; SI: symmetry index; 10WVT: $10 \mathrm{~m}$ walking velocity test; BBS: Berg Balance Scale. *: significantly different from pre-HESE, $\mathrm{p}<0.05$

gait patterns of hemiplegic patients and analyzing the related elements is meaningful ${ }^{16,17)}$. To contribute to the treatment of problems with gait, this study aimed to discover the effects of hip extension muscle strengthening on gait ability and stable gait. In the study, the experimental group showed significant improvements in walking speed, the affected side stance phase, stride length, and the stance phase symmetry index after the training. The HESE program conducted for the hemiplegic patients contributed to improvements in walking speed, stance phase, stride length, and the stance phase symmetry index. However, it did not affect gait ability or stable gait. The treatment with respect to movement after the acute phase improved hemiplegic patients' gait and function, similar to the results of a previous study ${ }^{18}$. In addition, in order to discover effective movement methods for hemiplegic patients besides general movement treatment, a muscle strengthening movement program using manipulations by a therapist was performed ${ }^{11)}$. In that study of the effects of leg muscle improvement movement and an aerobic movement program on muscle weakness and stiffness, thirteen stroke patients at least nine months after stroke onset were the subjects of a ten-week program ${ }^{11)}$. For about half an hour, the experimental group carried out resistance movements using a sand pocket, and Therabands of eight different elasticities, and also received a therapist's handling for the hip flexor and extensor, knee flexor and extensor, and ankle flexor and extensor muscles. The intervention improved their function. There was an increase in strength of about $42.3 \%$ in the leg muscles, and gait velocity also increased $^{11)}$. Moreover, in a study of the effects of gradual resistance movement on the leg muscle, involving twenty chronic stroke patients, gradual resistance movement by centripetal and centrifugal movement was conducted for eight weeks ${ }^{19)}$. As measured by computed tomography, there was a decline in hypoderm and the amount of body fat and an increase in midthigh muscle area of the femoral region ${ }^{19)}$. There was also an increase of the femoral muscles of about $9.0 \pm 4.5 \%$, and of gait velocity of about $48 \%{ }^{19)}$. Considering the results of previous studies of movement programs using gradual muscle movement and therapist handling, it seems that a treatment program using hip joint muscle strengthening movements and therapist handling provides an appropriate environment for improvement of gait ability and for motivation of patients. Wade et al. ${ }^{20)}$ reported that the $10-\mathrm{m}$ walking velocity test for hemiplegic patients is a simple, objective measurement for evaluating functional recovery. However, Sharp and Brouwer ${ }^{21)}$ reported that after a six-week intervention of knee joint isokinetic resistance movement involving fifteen chronic stroke patients, muscle power and gait velocity improved, whereas walking up and down stairs and TUG times showed no significant differences with respect to functional performance ability. Page ${ }^{22)}$ reported that the effect of movement treatment on stroke patients depends on the treatment time, the movement form, and the patient's positive participation. Hendricks et al. ${ }^{23)}$ suggested that the degree of recovery from stroke weakens as time passes and that the recovery of movement regulation ability occurs no later than three months after a stroke. A limitation of their study was that the disease period of the participants ranged from 6 months to 91 months, and no improvement of movement regulation function resulted. The reason why there was no significant improvement in all test items after four weeks of movement therapy was the order of movement and other factors during the intervention. To elicit an improvement in hemiplegic patients' stable gait, a much longer treatment period is required, and the stage and duration of stroke and a variety of forms of movement also need to be considered. From this it can be understood that for hip joint muscle power strengthening movements to influence hemiplegic patients' stable gait, several things are required at the same time: a long enough treatment period, a variety of movements and muscle power strengthening movements of the hip joint, knee joint, and ankle joint. Despite positive changes, the ability to generalize the present study's results to every hemiplegic patient is limited. Further study of more methods for improving stable gait through hip flexor muscle power strengthening movements is required, with larger numbers of participants, a longer treatment period, and a follow-up after the treatment. Furthermore, scientific multi-dimensional investigations on the effects of neurophysiotherapy related to gait and muscle function should be conducted for stroke patients ${ }^{24-30)}$.

\section{REFERENCES}

1) Eich HJ, Mach H, Werner C, et al.: Aerobic treadmill plus Bobath walking training improves walking in subacute stroke: a randomized controlled trial. Clin Rehabil, 2004, 18: 640-651. [Medline] [CrossRef]

2) Turnbull GI, Charteris J, Wall JC: Deficiencies in standing weight shifts by ambulant hemiplegic subjects. Arch Phys Med Rehabil, 1996, 77: 356-362. [Medline] [CrossRef]

3) Mumma CM: Perceived losses following stroke. Rehabil Nurs, 1986, 11: 19-24. [Medline] [CrossRef]

4) Perry J: Kinesiology of lower extremity bracing. Clin Orthop Relat Res, 1974, (102): 18-31. [Medline] [CrossRef]

5) Bohannon RW: Strength of lower limb related to gait speed and cadence in stroke patients. Physiother Can, 1986, 38: 204-206. [CrossRef]

6) Carr JH, Shepherd RB, Nordholm L, et al.: Investigation of a new motor assessment scale for stroke patients. Phys Ther, 1985, 65: 175-180. [Medline]

7) Don S, Reiker GG, Hildebolt C, et al.: Soft-copy versus hard-copy cranial sonography: intraobserver agreement and workstation efficiency. AJR Am J Roentgenol, 1997, 169: 555-561. [Medline] [CrossRef]

8) Dean CM, Richards CL, Malouin F: Task-related circuit training improves performance of locomotor tasks in chronic stroke: a randomized, con- 
trolled pilot trial. Arch Phys Med Rehabil, 2000, 81: 409-417. [Medline] [CrossRef]

9) Barbeau H, Visintin M: Optimal outcomes obtained with body-weight support combined with treadmill training in stroke subjects. Arch Phys Med Rehabil, 2003, 84: 1458-1465. [Medline] [CrossRef]

10) Hesse $S$, Uhlenbrock $D$, Werner $C$, et al.: A mechanized gait trainer for restoring gait in nonambulatory subjects. Arch Phys Med Rehabil, 2000, 81: 1158-1161. [Medline] [CrossRef]

11) Teixeira-Salmela LF, Olney SJ, Nadeau S, et al.: Muscle strengthening and physical conditioning to reduce impairment and disability in chronic stroke survivors. Arch Phys Med Rehabil, 1999, 80: 1211-1218. [Medline] [CrossRef]

12) Berg KO, Wood-Dauphinee SL, Williams JI, et al.: Measuring balance in the elderly: validation of an instrument. Can J Public Health, 1992, 83: S7-S11. [Medline]

13) Tong RK, Ng MF, Li LS, et al.: Gait training of patients after stroke using an electromechanical gait trainer combined with simultaneous functional electrical stimulation. Phys Ther, 2006, 86: 1282-1294. [Medline] [CrossRef]

14) Roth EJ, Merbitz C, Mroczek K, et al.: Hemiplegic gait. Relationship between walking speed and other temporal parameters. Am J Phys Med Rehabil, 1997, 76: 128-133. [Medline] [CrossRef]

15) Chen G, Patten C, Kothari DH, et al.: Gait deviations associated with poststroke hemiparesis: improvement during treadmill walking using weigh support, speed, support stiffness, and handrail hold. Gait Posture, 2005 , 22: 57-62. [Medline] [CrossRef]

16) Nilsson A, Vreede KS, Häglund V, et al.: Gait training early after stroke with a new exoskeleton - the hybrid assistive limb: a study of safety and feasibility. J Neuroeng Rehabil, 2014, 11: 92. [Medline] [CrossRef]

17) Mehrholz J, Elsner B, Werner C, et al.: Electromechanical-assisted training for walking after stroke. Cochrane Database Syst Rev, 2013, 7: CD006185. [Medline]

18) Duncan P, Studenski S, Richards L, et al.: Randomized clinical trial of therapeutic exercise in subacute stroke. Stroke, 2003, 34: 2173-2180. [Medline] [CrossRef]

19) Fiatarone MA, Marks EC, Ryan ND, et al.: High-intensity strength train- ing in nonagenarians. Effects on skeletal muscle. JAMA, 1990, 263: 3029 3034. [Medline] [CrossRef]

20) Wade DT, Wood VA, Heller A, et al.: Walking after stroke. Measurement and recovery over the first 3 months. Scand J Rehabil Med, 1987, 19: 2530. [Medline]

21) Sharp SA, Brouwer BJ: Isokinetic strength training of the hemiparetic knee: effects on function and spasticity. Arch Phys Med Rehabil, 1997, 78: 1231-1236. [Medline] [CrossRef]

22) Page SJ: Intensity versus task-specificity after stroke: how important is intensity? Am J Phys Med Rehabil, 2003, 82: 730-732. [Medline] [CrossRef]

23) Hendricks HT, van Limbeek J, Geurts AC, et al.: Motor recovery after stroke: a systematic review of the literature. Arch Phys Med Rehabil, 2002, 83: 1629-1637. [Medline] [CrossRef]

24) Jeon HJ, Kim MY, Lee JU, et al.: Differences in leg length discrepancy and weight distribution between the healthy and unhealthy sides of hemiplegic stroke patients. Toxicol Environ Health Sci, 2013, 5: 221-226. [CrossRef]

25) Kim JH, Kim MY, Lee JU, et al.: Waveform analysis of the brachial-ankle pulse wave velocity in hemiplegic stroke patients and healthy volunteers: a pilot study. J Phys Ther Sci, 2014, 26: 501-504. [Medline] [CrossRef]

26) Kim JH, Lee LK, Lee JU, et al.: A pilot study on the effect of functional electrical stimulation of stroke patients in a sitting position on balance and activities of daily living. J Phys Ther Sci, 2013, 25: 1097-1101. [Medline] [CrossRef]

27) Kim MY, Kim JH, Lee JU, et al.: Decrease of both cofilin and LIM kinase phosphorylation in the skeletal muscles of immobilization-induced atrophy rats. J Phys Ther Sci, 2014, 26: 355-357. [Medline] [CrossRef]

28) $\mathrm{Kim} \mathrm{MY}, \mathrm{Kim} \mathrm{JH}$, Lee JU, et al. The effects of functional electrical stimulation on balance of stroke patients in the standing posture. J Phys Ther Sci, 2012, 24: 77-81. [CrossRef]

29) Lee JU, Kim JH, Kim MY, et al.: Increase of myoglobin in rat gastrocnemius muscles with immobilization-induced atrophy. J Phys Ther Sci, 2013, 25: 1617-1620. [Medline] [CrossRef]

30) Lee WD, Lee JU, Kim J: Differences in amplitude of functional electrical stimulation between the paretic and nonparetic sides of hemiplegic stroke patients. Toxicol Environ Health Sci, 2013, 5: 82-85. [CrossRef] 